\title{
Transvaginal Cystocele Repair by Purse-String Technique Reinforced with Three Simple Sutures: Surgical Technique and Results
}

\author{
Ho-Sook Song ${ }^{\star}$ Gwoan Youb Choo*, Long-Hu Jin ${ }^{1}$, Sang-Min Yoon, Tack Lee \\ Department of Urology, Inha University School of Medicine, BK 21 Project, Incheon, Korea; ${ }^{1}$ Department of Urology, Shanghai Tenth People’s Hospital, \\ Tongji University School of Medicine, Shanghai, China
}

\begin{abstract}
Purpose: Different techniques for cystocele repair including the conventional anterior colporrhaphy and mesh technique are known. Our goal was to evaluate the anatomical success and safety of our method of transvaginal anterior vaginal wall repair by the purse-string technique reinforced with three simple additional sutures in the repair of cystocele over a 4-year follow-up period.

Methods: This was a retrospective review of 69 consecutive patients (grades 2 to 4 ) who underwent the above operations between 2001 and 2011, including their success rates as assessed by use of the Baden-Walker halfway classification system.

Results: Of the patients, 62 patients (98\%) were completely cured of cystocele and 1 patient showed grade 2 cystocele recurrence that required no further treatment. Two patients with grade 4 cystocele were completely cured. There was no vaginal erosion related to the cystocele repair.

Conclusions: Transvaginal anterior colporrhaphy by a purse-string technique reinforced with simple additive sutures appears to be a simple, safe, and easily performed approach in cystocele repair. There is no need for other material for reinforcement, even in high-grade cystocele, which is an advantage of our technique.
\end{abstract}

Keywords: Urinary bladder diseases; Prolapse; Vagina; Retrospective studies; Surgery

\section{INTRODUCTION}

Cystocele is a prolapse of the anterior vaginal wall with herniation of the bladder [1]. This suggests that the bladder is shifted out of its normal anatomical position and its fallen base through the anterior vaginal wall has been relaxed and elongated in both an anteroposterior and a lateral direction. This can result from the central or lateral weakness of a pubocervical fascia between the bladder and the vagina [2]. To restore the normal anatomical position by strengthening the weakness, the conventional method of anterior colporrhaphy has been used, which requires plication and pulling the lateral tissues from side to side together in the midline $[3,4]$. This may allow the weakness of the an- terior wall in the anteroposterior direction to remain unsolved, however, which could result in recurrence. Comiter et al. [1] and Chen et al. [5] have used purse-string sutures to pull the relaxed tissues together in the center from all directions. However, women who undergo conventional anterior colporrhaphy have been known to develop cystocele recurrence, with a high incidence of 30 to $70 \%$ [6-8], although there is a paucity of results according to the different techniques.

The goal of cystocele repair is to reinforce the natural wall between the vagina and the bladder, which has failed to support the pelvic organs such as the bladder. Thus, the aim of our study was to determine the effectiveness of transvaginal anterior colporrhaphy by a purse-string technique reinforced with simple
Corresponding author: Tack Lee

Department of Urology, Inha University School of Medicine, 5th Floor, C-Dong, 366 Seohae-daero, Jung-gu, Incheon 400-103, Korea

Tel: +82-32-890-3448 / Fax: +82-32-890-3097 / Email: lee.tack33@gmail.com

*These authors contributed equally to this study.

Submitted: September 15, 2012 / Accepted after revision: September 27, 2012
This is an Open Access article distributed under the terms of the Creative Commons Attribution Non-Commercial License (http://creativecommons.org/licenses/by-nc/3.0/) which permits unrestricted non-commercial use, distribution, and reproduction in any medium, provided the original work is properly cited. 
additive sutures in the treatment of the cystocele. We analyzed both surgical outcomes and complications.

\section{MATERIALS AND METHODS}

A retrospective analysis of data collected for 69 patients who underwent transvaginal anterior colporrhaphy with double-layer cystocele closure of first a purse-string suture and then simple reinforced sutures between January 2001 and December 2011 was performed. The classification of cystoceles was based on the Baden-Walker halfway system [9]. A review of the medical records consisted of medical and surgical history, preoperative cystocele staging and voiding symptoms, postoperative complications, and cystocele recurrence. The inclusion criterion was a grade 2 to 4 cystocele without regard to the presence or absence of the uterus; patients with vault prolapse were excluded. All patients underwent a physical examination by the same urologist before and after the operation. All operative procedures were performed by the same urologist, and the operation for stress urinary incontinence was performed at the same time as the cystocele repair in all patients. Every visit included clinical examination and questions concerning lower urinary tract symptoms, including storage symptoms (i.e., frequency, urgency, urinary incontinence, and nocturia), voiding symptoms (i.e., hesitancy, weak urine stream, straining, intermittency, and dysuria), postmicturition symptoms (i.e., feeling of incomplete voiding), and pain (i.e., dyspareunia, lower abdominal pain). Operation failure was defined as any degree of descent greater than grade 1 noted at the follow-up visit. Recurrent cystocele was defined as grade 2 or higher noted any time after the first follow-up visit. The length of follow-up was defined as the interval by month from the date of surgery through the date of last contact. The study received institutional review board approval for this retrospective analysis.

We routinely performed preoperative urodynamic studies including post-void residual urine measurement and Valsalva stress test in all patients. If there was a hypocontractile or acontractile detrusor on urodynamics, the operation for cystocele was not recommended to the patient.

\section{Surgical Technique}

Cystocele repair was performed with a pubovaginal sling, such as the transvaginal or transobturator tape (TVT or TOT, respectively). Other concomitant procedures, such as hysterectomy or operation for the posterior compartment, were performed by another urogynecologist as clinically indicated.

For cystocele repair, with patients in the dorsal lithotomy position, the incision site of the anterior vaginal epithelium was injected with a vasoconstrictive agent (Pitressin diluted $20 \mathrm{U}$ in $80 \mathrm{~mL}$ of saline). A midline incision on the vaginal epithelium was made from the bladder neck to the anterior fornix, followed by dissection of the vaginal epithelium from the underlying pubocervical fascia. Then, the author used a Vicryl \#2 suture placed in a continuous circular clockwise fashion, starting from 3 o'clock through 5, 7, 9, 11, and 1 o'clock (Fig. 1). At this time, the suture was placed on the tissues attached strongly to the surrounding bones or cervix as soon as possible. The floor of the bladder was then pushed up as the purse-string suture was
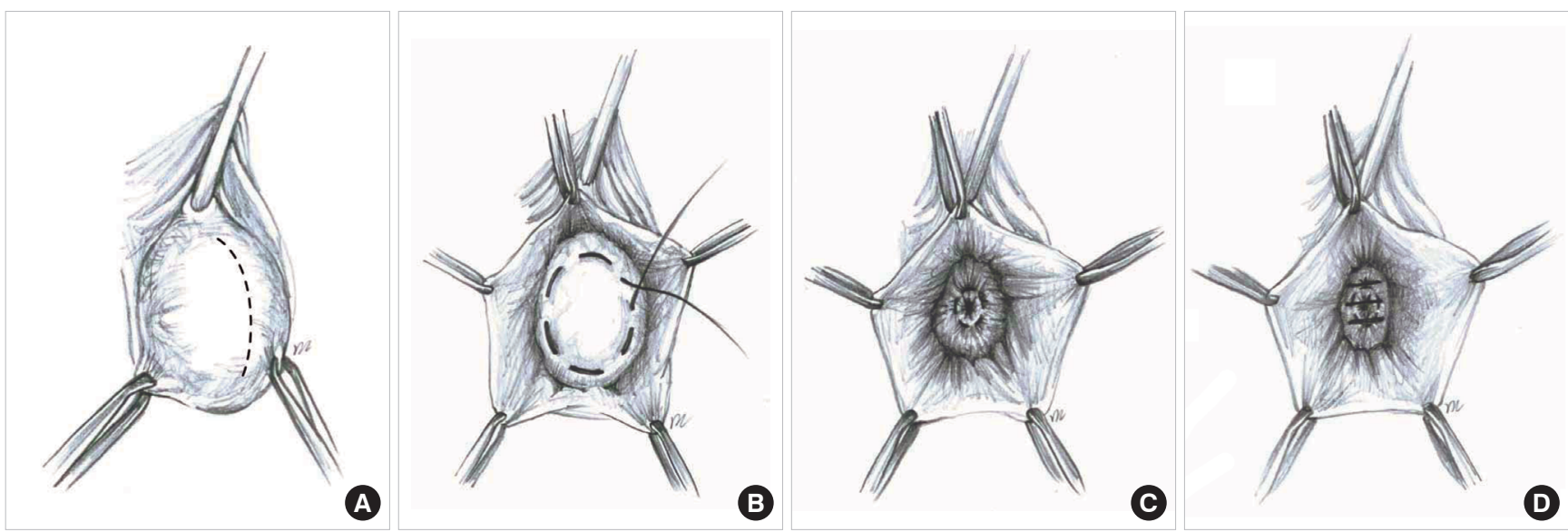

Fig. 1. Surgical procedures. (A) The dotted line indicates the incision site for this operation. (B) Use of purse-string suture technique starting from 3 o'clock to 1 o'clock in a clockwise fashion. (C) The floor of the bladder was then pushed up as the purse-string suture was tied. (D) The lateral tissues were plicated over the area of the purse-string suture at three points. 
tied. After that, the lateral tissues were plicated over the area of the purse-string suture at three points for reinforcement. The excess vaginal epithelium was excised and the epithelial margins were approximated in the midline with interrupted sutures.

In patients with urodynamic stress urinary incontinence, the TVT or TOT procedure was performed separately after completion of anterior colporrhaphy. This surgical procedure was performed in a different incision from that for cystocele repair.

\section{Statistical Analysis}

All analyses were performed with GraphPad Prism ver. 5.03 (GraphPad Software Inc., La Jolla, CA, USA). Statistical analysis was performed using a Wilcoxon rank test to compare preoperative and postoperative grades. Values of $\mathrm{P}<0.05$ were considered statistically significant.

\section{RESULTS}

The clinical characteristics of the patients are listed in Table 1. A total of 63 consecutive patients were available during the period. We reported only on those patients who completed all of the data components of follow-up to avoid uncertainty regarding data interpretation. Preoperatively, 29 patients (46\%) had grade 2 and 32 (51\%) had grade 3 cystocele. Also, 2 patients (3\%) had grade 4 cystocele and showed signs of infection with multiple stones on their first visit. They required antibiotics for a period of time before the operations.

Table 1. Preoperative clinical characteristics of the patients

\begin{tabular}{lc}
\hline Characteristic & Value \\
\hline Age $(\mathrm{yr})$ & $49(34-72)$ \\
Body weight $(\mathrm{kg})$ & $64(47-83)$ \\
Body mass index $\left(\mathrm{kg} / \mathrm{m}^{2}\right)$ & \\
$25-30$ & $33(52)$ \\
$>30$ & $22(35)$ \\
Hysterectomy & $9(14)$ \\
Diabetes mellitus & $4(6)$ \\
Hypertension & $15(24)$ \\
Prolapse grade (Baden-Walker halfway system) & \\
2 & $29(46)$ \\
3 & $32(51)$ \\
4 & $2(2)$ \\
\hline
\end{tabular}

Values are presented as median (range) or number (\%).
Of the patients, 62 patients (98\%) were completely cured of cystocele and 1 patient showed grade 2 cystocele recurrence that required no further treatment. In particular, two patients with grade 4 cystocele were completely cured.

The mean follow-up was 49 months (range, 3 to 145 months). All of the patients underwent concomitant TVT or TOT procedures for coexistent urodynamic stress incontinence. All patients showed no stress incontinence through their last follow-up. A total of 17 patients (27\%) underwent rectocele repair by one urogynecologist at the same time of cystocele repair and showed no recurrence. However, two patients complained of a narrow vaginal canal 3 months after the operation.

Table 2 summarizes the results of the preoperative and postoperative voiding symptoms. Many symptoms disappeared after the operations, but two cases of postoperative urgency had preexisting urgency before their operation. Urge incontinence developed newly in two patients (3\%) after the operation, which may have been related to chronic interstitial cystitis.

Intraoperatively, blood transfusion was required in four patients, which were early cases in our experience with this operation. We experienced three postoperative complications. Three women had wound dehiscence that developed in the TVT mesh wound.

Recently, it is routine practice in our hospital to remove the urinary catheter and discharge the patient on the first postoperative day.

\section{DISCUSSION}

Cystocele repair has been a challenge to pelvic floor surgeons. Because of the known high failure rate of conventional methods, use of a graft or mesh as a reinforcing material has been

Table 2. Presenting voiding symptoms and postoperative changes after 3 months of follow-up

\begin{tabular}{lcc}
\hline Voiding symptom & Preoperative & Postoperative \\
\hline Frequency & $50(79)$ & $0(0)$ \\
Urgency & $37(59)$ & $1(2)$ \\
Urge incontinence & $31(49)$ & $2(3)$ \\
Residual urine sense & $1(2)$ & $1(2)$ \\
Hesitancy & $5(8)$ & $0(0)$ \\
Intermittency & $2(3)$ & $0(0)$ \\
Stress urinary incontinence & $63(100)$ & $0(0)$ \\
\hline
\end{tabular}

Values are presented as number (\%). 
popularized, but specific complications related to these procedures have begun to be clarified. Such complications include erosion, infection, contraction, de novo dyspareunia, and chronic pain $[6,10,11]$. Our study showed that even with conventional cystocele repair, with an appropriate reinforcing method it is possible to achieve excellent results in the repair of cystocele. Furthermore, in the long-term follow-up, the incidence of postoperative complications compared favourably with previously published results for conventional or mesh studies [7,11]. Thus, our method of conventional cystocele repair with purse-string and simple, additive reinforced sutures compared favorably with previous conventional or mesh studies, showed no recurrence of cystocele, and showed no increased postoperative voiding problems.

Cystocele is known to occur as a result of a central or lateral defect. The central defect develops as the result of a defect in the pubocervical fascia in the center of the anterior vaginal wall, and the lateral defect occurs by detachment of the pubocervical fascia from the tough tendinous arcus on each side. The central defect has been known to account for 5 to $15 \%$ of cystocele occurrences, and the lateral defect for 70 to $80 \%[9,12]$. However, the defects may be present simultaneously $[2,13]$, and in our experience, the most common defect was a combined central and lateral defect in the anterior vaginal wall. Therefore, it does not seem to be reasonable to use a surgical technique according to the defect type of the cystocele, although a number of techniques for the repair of cystoceles have been reported in the literature and some trials have been conducted to determine which surgical procedure is needed according to the defect type $[3,12,14]$.

The goal of cystocele repair is to restore the normal anatomical position of the bladder [15], which is located on the upper side of the imaginary line between the bilateral ischio-pubic ramus. To achieve this goal, we placed a purse-string suture laterally in the strong tendinous arch and posteriorly in the anterior surface of the cervix to create strengthened support for the bladder. This purse-string technique has the advantage of elevating the relaxed bladder base to the more higher anatomical position, compared with other operations using graft or mesh, but the disadvantage of anterior displacement of the cervix owing to the shortening between the bladder neck and the cervix. We could see the elevated bladder neck by cystoscopy after making the purse-string suture in the anterior vaginal wall, which suggests elevation of the relaxed and elongated posterior floor of the bladder. Chen et al. [5] has pointed out that this as an ab- normal inversion of the bladder and can result in decreased bladder capacity and increased storage symptoms. In our experience, however, this is not an inversion but a restoration of the elongated and relaxed bladder base to the normal original position. In our experience with cystoscopy, after 1 month, this elevation disappeared and caused no decreased voiding volume nor increased overactive symptoms in these patients. On the other hand, in the operation using mesh, the bladder is usually reinforced with graft or mesh in a slightly bulged condition, and there seems to be confusion as to which position is normal and if the other position is an adverse condition for the bladder.

Previous reports have shown a high recurrence rate with the purse-string cystocele repair method, including the plication and purse-string methods $[4,11]$. Owing to this high recurrence rate, various modified techniques have been advocated to improve the cure rate. Chen et al. [5] used an additional small synthetic mesh on the purse-string sutured area to decrease recurrence. However, we used only three additional plication sutures instead of this mesh on the purse-string sutured area, and our success and complication rates were comparable with other studies using synthetic mesh. The present study had some shortcomings, which include its retrospective nature, small sample size and a lack of validated questionnaires. Furthermore, this method is not effective for patients with vaginal vault prolapse, which requires another operation such as sacrocolpopexy. Nonetheless, we are encouraged by our successful results in these patients with cystocele.

In conclusion, transvaginal anterior colporrhaphy using a purse-string technique reinforced with simple additive sutures for cystocele repair appears to be a good approach. The technique is simple, safe, and easily performed and require no additional materials for reinforcement, even in high-grade cystocele. The operation showed a low failure rate and low morbidity, although long-term data are warranted to provide adequate information.

\section{CONFLICTS OF INTEREST}

No potential conflict of interest relevant to this article was reported.

\section{ACKNOWLEDGEMENTS}

This work was supported by an Inha University research grant. 


\section{REFERENCES}

1. Comiter CV, Vasavada SP, Raz S. Transvaginal culdosuspension: technique and results. Urology 1999;54:819-22.

2. Safir MH, Gousse AE, Rovner ES, Ginsberg DA, Raz S. 4-Defect repair of grade 4 cystocele. J Urol 1999;161:587-94.

3. Kelly HA, Dumm WM. Urinary incontinence in women, without manifest injury to the bladder. 1914. Int Urogynecol J Pelvic Floor Dysfunct 1998;9:158-64.

4. Bump RC, Hurt WG, Theofrastous JP, Addison WA, Fantl JA, Wyman JF, et al. Randomized prospective comparison of needle colposuspension versus endopelvic fascia plication for potential stress incontinence prophylaxis in women undergoing vaginal reconstruction for stage III or IV pelvic organ prolapse. The Continence Program for Women Research Group. Am J Obstet Gynecol 1996;175:326-33.

5. Chen CH, Hsiao SM, Chang TC, Wu WY, Lin HH. Transvaginal cystocele repair using pursestring technique reinforced with customtailored two-armed mesh. Urology 2011;78:1275-80.

6. Sand PK, Koduri S, Lobel RW, Winkler HA, Tomezsko J, Culligan PJ, et al. Prospective randomized trial of polyglactin 910 mesh to prevent recurrence of cystoceles and rectoceles. Am J Obstet Gynecol 2001;184:1357-62.

7. Weber AM, Walters MD, Piedmonte MR, Ballard LA. Anterior colporrhaphy: a randomized trial of three surgical techniques. Am J Obstet Gynecol 2001;185:1299-304.
8. Olsen AL, Smith VJ, Bergstrom JO, Colling JC, Clark AL. Epidemiology of surgically managed pelvic organ prolapse and urinary incontinence. Obstet Gynecol 1997;89:501-6.

9. Kobashi KC, Leach GE, Chon J, Govier FE. Continued multicenter followup of cadaveric prolapse repair with sling. J Urol 2002;168: 2063-8.

10. Migliari R, Usai E. Treatment results using a mixed fiber mesh in patients with grade IV cystocele. J Urol 1999;161:1255-8.

11. Mourtialon P, Letouzey V, Eglin G, de Tayrac R; French Ugytex Study Group. Cystocele repair by vaginal route: comparison of three different surgical techniques of mesh placement. Int Urogynecol J 2012;23:699-706.

12. Richardson AC, Edmonds PB, Williams NL. Treatment of stress urinary incontinence due to paravaginal fascial defect. Obstet Gynecol 1981;57:357-62.

13. Rodriguez LV, Bukkapatnam R, Shah SM, Raz S. Transvaginal paravaginal repair of high-grade cystocele central and lateral defects with concomitant suburethral sling: report of early results, outcomes, and patient satisfaction with a new technique. Urology 2005;66(5 Suppl):57-65.

14. Shull BL, Baden WF. A six-year experience with paravaginal defect repair for stress urinary incontinence. Am J Obstet Gynecol 1989; 160:1432-9.

15. Ng CC, Chong CY. The effectiveness of transvaginal anterior colporrhaphy reinforced with polypropylene mesh in the treatment of severe cystoceles. Ann Acad Med Singapore 2006;35:875-81. 